\title{
Open access publisher
}

Public Domain

\section{Source}

Open Research Glossary

A publisher that publishes all research articles as open access articles. Most legacy

publishers have options to make journals at least partially open access. 